\title{
Ligophorus uruguayense sp. nov. (Monogenea, Ancyrocephalidae), a gill parasite from Mugil platanus (Mugiliformes, Mugilidae) in Uruguay
}

\author{
Gabriela Failla Siquier ${ }^{1 *}$ and Margarita Ostrowski de Núñez ${ }^{2}$ \\ ${ }^{1}$ Laboratorio de Zoologia de Invertebrados, Departamento de Biología Animal, Facultad de Ciencias, Iguá $42258^{\circ}$ S. Universidad \\ de la República, Montevideo 11400, Uruguay; ${ }^{2}$ Departamento de Ciencias Biológicas, \\ Facultad de Ciencias Exactas y Naturales, Universidad de Buenos Aires, Ciudad Universitaria, Pabellón II, 1428 Buenos Aires, Argentina
}

\begin{abstract}
The present study describes a new species, Ligophorus uruguayense, parasitizing the gills of Mugil platanus Günther, 1880 from the coast of Uruguay. It differs from all other species of the genus mainly in the shape of the ventral bar, the thick process at the distal end of the inner root of ventral anchors, the J-shaped penis accessory piece and the vaginal tube showing transverse annulations at its distal end, the host species, and geographical distribution. This is the first description of a species of Ligophorus from a mullet in the South Atlantic Ocean.
\end{abstract}

\section{Keywords}

Monogenea, Ligophorus, gill parasites, Mugil platanus, mullets, Uruguay, South Atlantic Ocean

\section{Introduction}

The fish species of the family Mugilidae have a wide geographic distribution and are mainly restricted to coastal estuarine waters of tropical and subtropical regions. The taxonomic status of Mugil platanus Günther, 1880 is still controversial, with some authors considering it as a distinct population of Mugil cephalus Linnaeus, 1758 (see Fraga et al. 2007), and others as a different species (Castro et al. 2008). The parasites of mullets have been thoroughly studied because of their importance for human consumption (Paperna and Overstreet 1981, Juárez-Arroyo and Salgado-Maldonado 1989, VallesRíos et al. 2000). The species of the monogenean genus Ligophorus Euzet et Suriano, 1977 have received considerable attention in the past few years. The genus Ligophorus was established for species recovered from Mediterranean mugilids. In the Northern Hemisphere, new species of Ligophorus were found parasitizing mugilid species from the Black Sea, Azov Sea, Mediterranean Sea, North Atlantic Ocean, and Pacific Ocean (Dmitrieva and Gerasev 1996; Sarabeev and Balbuena 2004; Sarabeev et al. 2005; Rubtsova et al. 2006, 2007; Dmitrieva et al. 2007). In the Southern Hemisphere the only species so far described is L. huitrempe Fernández Bargiela, 1987 from a mugilid in the Chilean coast, Pacific Ocean.
The present study describes a new species of Ligophorus, and is the first report of this genus parasitizing Mugil platanus from the South Atlantic Ocean.

\section{Materials and methods}

Mugil platanus specimens were collected from the coastal lagoon Laguna de Rocha $\left(34^{\circ} 33^{\prime}-34^{\circ} 41^{\prime} \mathrm{S}\right.$ and $54^{\circ} 02^{\prime}-$ $\left.54^{\circ} 22^{\prime} \mathrm{W}\right)$, Uruguay, in 1993 and 1994. Fish were dissected in the field, and their gills and other organs were immediately removed and fixed in $4 \%$ formalin. In the laboratory, gills were examined under a stereoscopic microscope. Ancyrocephalid monogeneans were cleared in lactophenol (Amman) and mounted in glycerine jelly or stained with chlorhydric carmine (Langeron 1942), dehydrated in an ethanol series and mounted in Canada balsam. To study live monogeneans additional mugilids of the same species were captured in 2007 from Las Flores $\left(34^{\circ} 50^{\prime} \mathrm{S}-55^{\circ} 25^{\prime} \mathrm{W}\right)$, Department of Maldonado, Uruguay.

A total of twenty-five characters of sclerotized structures were measured, of which twenty-two were defined by Mariniello et al. (2004), Sarabeev and Balbuena (2004), and Rubtsova et al. (2007), and the remaining three are defined here, namely distance between upper and lower lobe of the penis ac- 

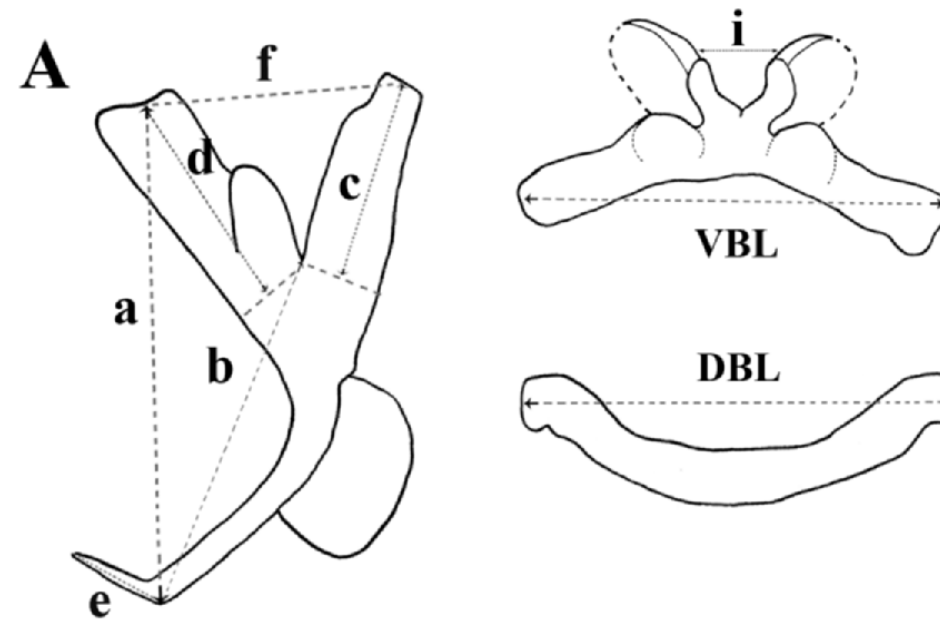

B
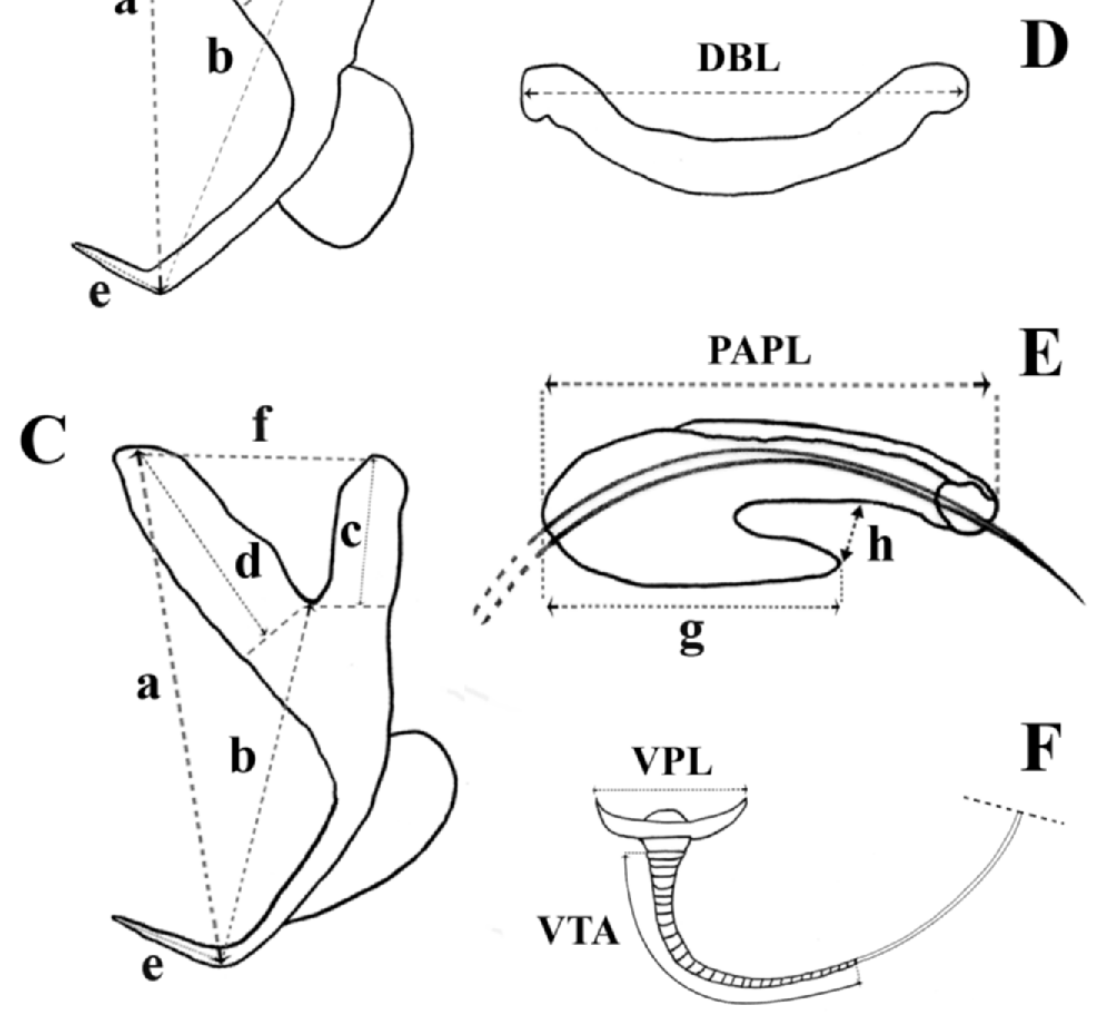

Fig. 1. Diagram showing measurements of the sclerotized structures: $\mathbf{A}$ - ventral anchor, $\mathbf{B}$ - ventral bar, $\mathbf{C}-$ dorsal anchor, $\mathbf{D}-$ dorsal bar, $\mathbf{E}$ - J-shaped accessory piece of the male copulatory complex, $\mathbf{F}$ - vaginal armament (see Table II for abbreviations of metric variables)

cessory piece; the vaginal plate (corresponding to the saucershaped opening); and the vaginal ring (corresponding to transverse annulations at the distal end). All these structures were measured on fixed and live specimens, except the vaginal plate and the vaginal ring, which were measured on live specimens only. The abbreviations of the characters used throughout the text, and the measurements in micrometers, with the mean followed by the standard deviation (SD) within parentheses, range and number of specimens measured (n), are given in Table II. A diagram showing measurements of the sclerotized elements is presented in Figure 1. Drawings were made with the aid of a camera lucida attached to an Olympus BX-50 microscope. Micrographs were taken with a Sony Cyber-shot 6.0 DSC-S600 digital camera. Representative specimens were mounted in Canada balsam and deposited in the Helminthological Collection of the Laboratorio de Zoología de Invertebrados, Facultad de Ciencias, Montevideo, Uruguay, and in the Helminthological Collection of the Museo Argentino de Ciencias Naturales "Bernardino Rivadavia", Buenos Aires, Argentina. Data were analyzed with $\chi^{2}$ test and Mann-Whitney U-test.

\section{Results}

Thirty-one out of 123 fish collected in 1993 and 1994 were found infected with a new species of Ligophorus. Specimens were recovered from both the right and left gill arches, with a higher number of parasites on the first and second gill arches

Table I. Distribution of parasites on gill arches from 123 specimens of Mugil platanus

\begin{tabular}{lcc} 
Site & $\begin{array}{c}\text { Ligophorus } \\
\mathrm{n}\end{array}$ & $\begin{array}{c}\% \\
\text { (n) }\end{array}$ \\
\hline Total & 411 & 100 \\
Left side & 204 & 49.6 \\
Right side & 207 & 50.4 \\
Gill arch 1 & 149 & 36 \\
Gill arch 2 & 115 & 28 \\
Gill arch 3 & 98 & 24 \\
Gill arch 4 & 49 & 12 \\
External hemibranches & 247 & 60 \\
Internal hemibranches & 164 & 40 \\
\hline
\end{tabular}




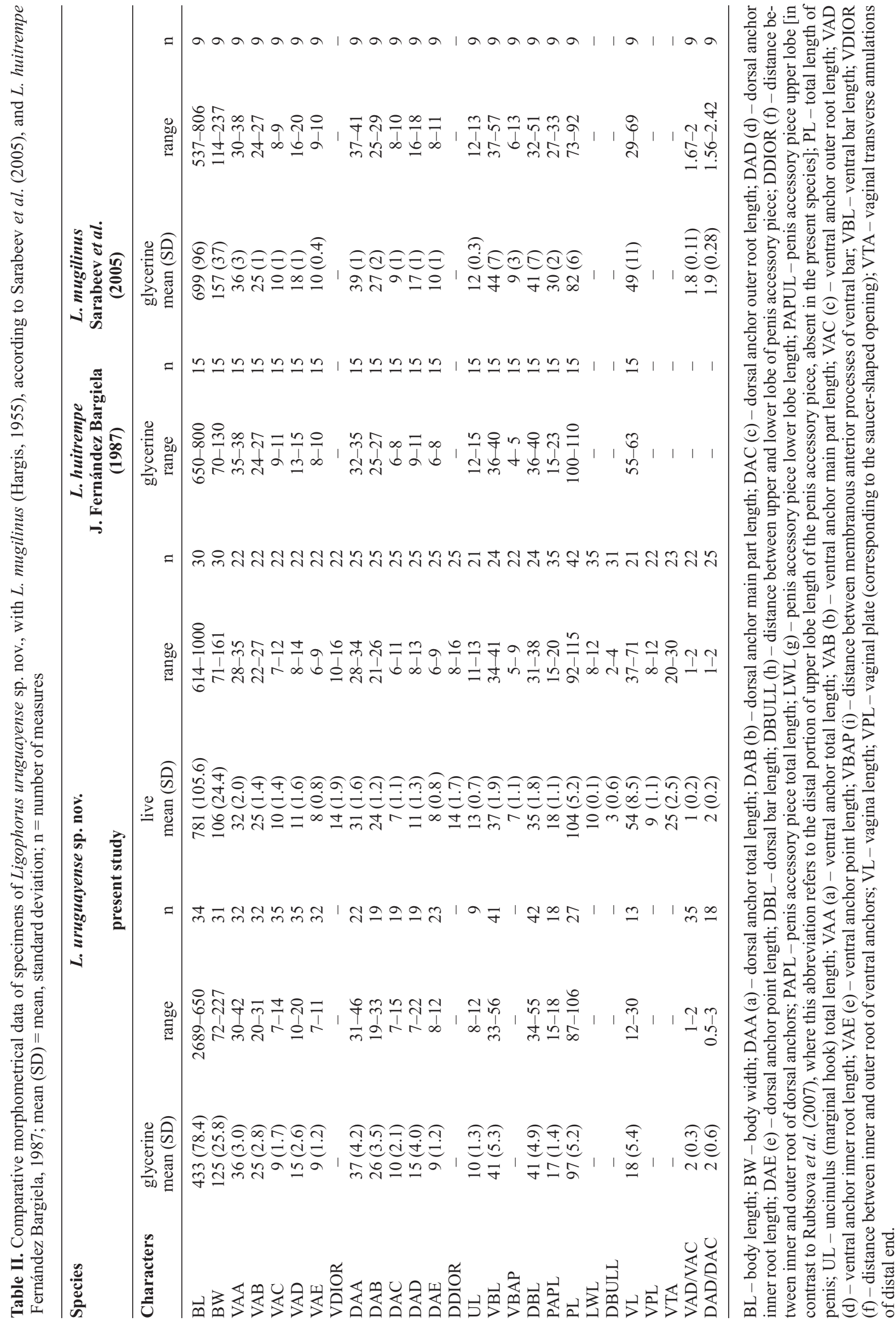


(Table I). Prevalence of infection was $25.2 \%$ and mean intensity 13.7 (24.0) worms per fish.

\section{Ligophorus uruguayense sp. nov. (Figs 2-4)}

Description: Worms with characters of the genus as defined by Euzet and Suriano (1977) and supplemented by Sarabeev and Balbuena (2004). Table II shows the morphometric measurements of fixed and live specimens of the studied species and

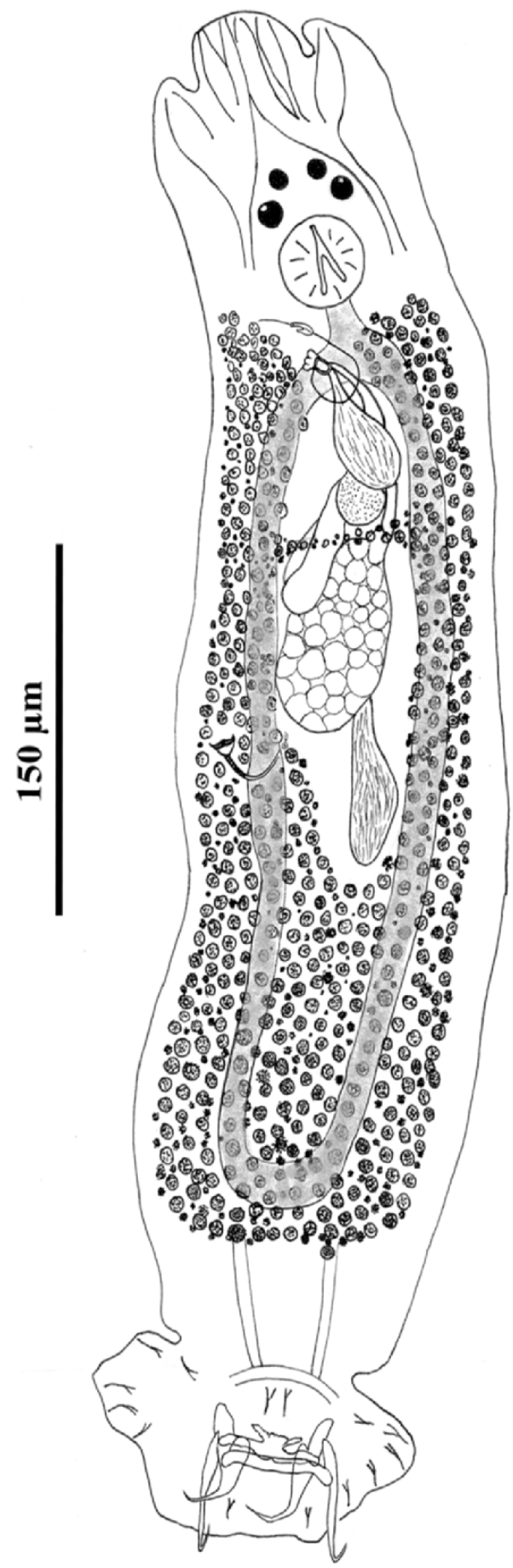

Fig. 2. Ligophorus uruguayense sp. nov.: Adult, ventral view those of L. huitrempe (Southern Pacific Ocean) and L. mugilinus (Hargis 1955) (North Atlantic Ocean) for comparison.

Body fusiform, with two pairs of pigmented eye-spots, posterior one with lens. Posterior haptor armed with 14 uncinuli (Fig. 2). One pair of ventral anchors connected by ventral transverse bar (Figs 3A, 4A), one pair of dorsal anchors connected by dorsal transverse bar (Figs 3B, 4A). Ventral anchors with elongate thin blade and recurved point, forming obtuse angle (about $100^{\circ}$ ). Base of anchor markedly thicker than blade, separated by a notch. Inner root (guard) somewhat longer than outer root (shaft), VAD/VAC $=1.2 \pm 0.2(1.0-1.5 ; \mathrm{n}=22)$. Inner root shows thick process at distal end where ventral connecting bar articulates with anchor. Angle between roots about $50^{\circ}$. Filaments present. Ventral connecting bar massive, slightly curved, with two sclerotized thickenings at base of two membranous anterior medial processes; heavily sclerotized median process between open $\mathrm{V}$-shaped membranous processes (not always seen in stained specimens) (Figs 3A, 4A). Dorsal anchors similar in shape to ventral anchors (except for thick process at distal end of inner root (Fig. 4B). Inner root much longer than outer root, $\mathrm{DAD} / \mathrm{DAC}=1.5 \pm 0.2(1.0-2.0$; $\mathrm{n}=25$ ). Base of dorsal anchors somewhat thinner than that of ventral anchors. Dorsal transversal bar slightly V-shaped, with rounded ends (Figs 3B, 4A). All 14 uncinuli similar in shape and size, with slightly curved handle and sickle (Fig. 3C). Male copulatory complex consisting of tubular penis about $1.0 \mu \mathrm{m}$ in diameter and with J-shaped accessory piece, showing short lower lobe joined to longer, simple and tubular upper lobe at proximal end, separated by short distance (Figs 3E, 4C, 4D). Accessory piece supports distal end of penis. Vaginal armament constituted by convoluted, sclerotized tube; two proximal thirds thin, distal third thick; transverse annulations at distal end; with wide saucer-shaped opening (Figs 3D, 4E) placed submidventrally.

Type host: Mugil platanus Günther, 1880.

Site of infection: Gill lamellae.

Type locality: Laguna de Rocha $\left(34^{\circ} 33^{\prime}-34^{\circ} 41^{\prime} \mathrm{S}\right.$ and $\left.54^{\circ} 02^{\prime}-54^{\circ} 22^{\prime} \mathrm{W}\right)$, Department of Rocha, Uruguay.

Other localities: Las Flores ( $\left.34^{\circ} 50^{\prime} \mathrm{S}-55^{\circ} 25^{\prime} \mathrm{W}\right)$, Department of Maldonado, Uruguay.

Prevalence and intensity range: $\mathrm{P}=25.2 \%$; intensity range 1-113 worms per fish

Specimens deposited in the Helminthological Collection of the Laboratorio de Zoología de Invertebrados, Facultad de Ciencias, Montevideo, Uruguay, AP/12192-12196; and in the Helminthological Collection of the Museo Argentino de Ciencias Naturales "Bernardino Rivadavia", Buenos Aires, Argentina, MACN-Pa 477/1-4.

Etymology: The specific name refers to the geographic location where the worm was found.

Remarks: There were significant differences in the measurements of characters between live and glycerine- or balsammounted specimens (Table II), except in the following: VAB $(\mathrm{U}=0.54 ; \mathrm{p}=0.58 ; \mathrm{n}=22), \mathrm{DAB}(\mathrm{U}=1.67 ; \mathrm{p}=0.09 ; \mathrm{n}=25)$, $\operatorname{VBL}(\mathrm{U}=0.96 ; \mathrm{p}=0.33 ; \mathrm{n}=24)$ and PAPL $(\mathrm{U}=0.75 ; \mathrm{p}=0.45$; 

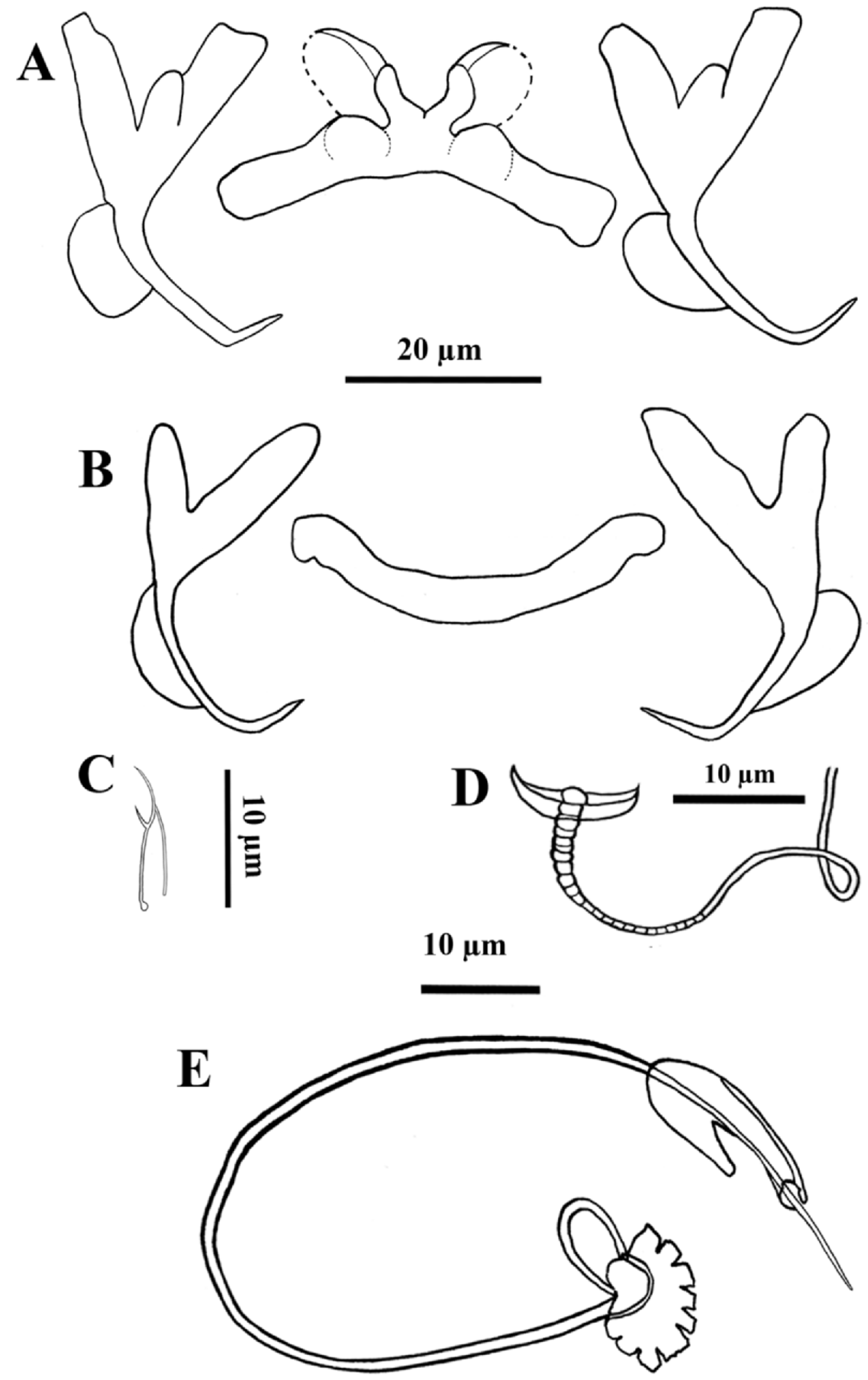

Fig. 3. Sclerotized pieces of Ligophorus uruguayense sp. nov.: A - ventral bar and anchors, B - dorsal bar and anchors, $\mathbf{C}-$ marginal hook, $\mathbf{D}$ - vaginal armament, $\mathbf{E}$ - male copulatory complex: penis and accessory piece 

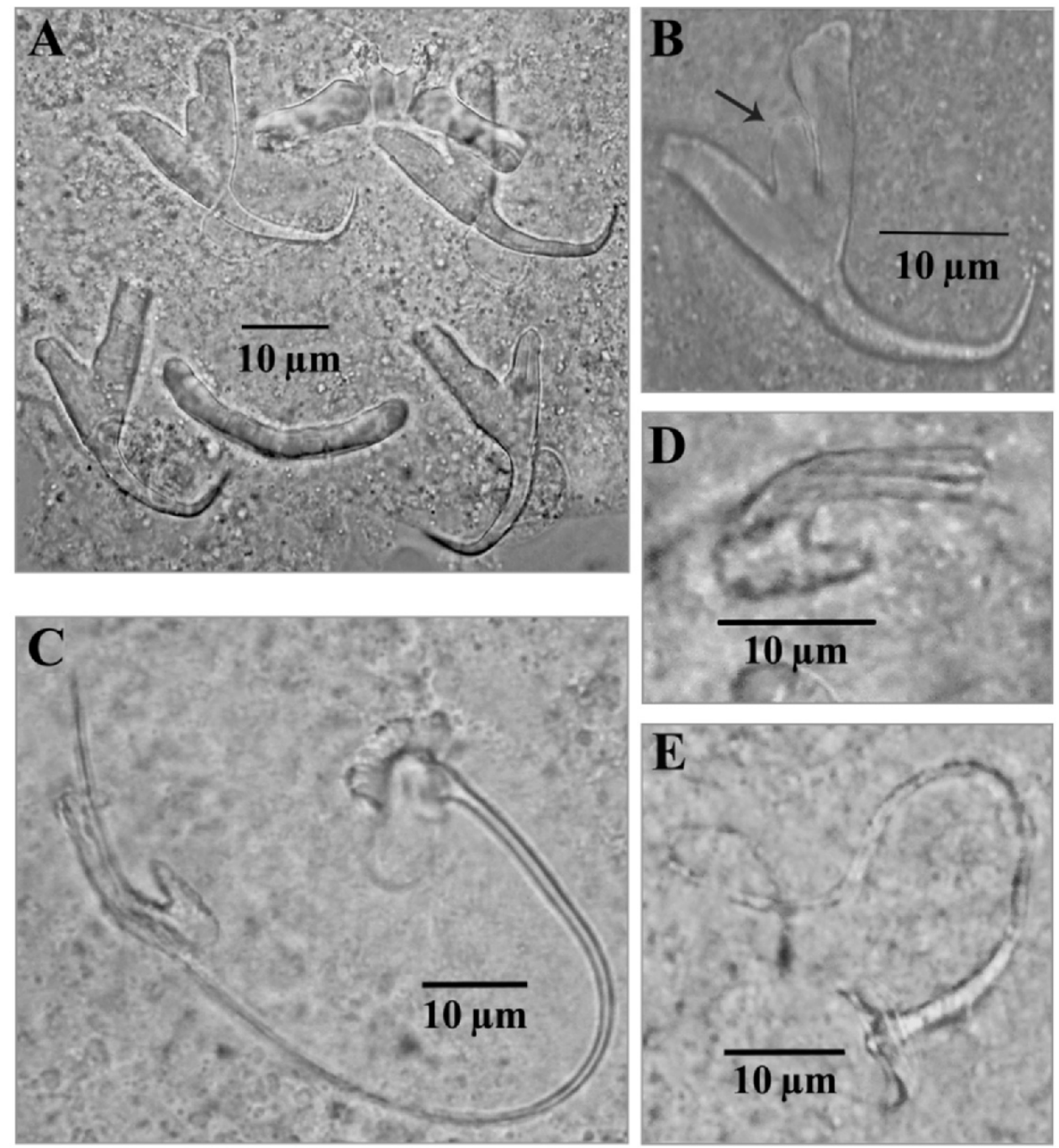

Fig. 4. Photomicrographs of sclerotized elements of haptor, male copulatory complex and vaginal armament of Ligophorus uruguayense sp. nov.: A - dorsal bar, ventral bar and anchors, $\mathbf{B}$ - detail of the distal thick process (arrow) of the inner root (guard), $\mathbf{C}-$ male copulatory complex, $\mathbf{D}$ - detail of the J-shaped accessory piece of the male copulatory complex, $\mathbf{E}$ - vaginal armament

$n=35)$. Thus, the characters that were not affected by the mounting methods used are the ventral bar (VBL), the ventral (VAB) and dorsal (DAB) anchor main part lengths and the accessory piece (PAPL) of the male copulatory complex. The ventral bar is a heavily sclerotized piece rather than a slightly curved piece and its morphology remained unchanged. On the contrary, the dorsal bar is less sclerotized, and its shape was modified by the pressure of the coverslip. No significant differences were found in the distance between shaft and guard of both ventral and dorsal anchors in live specimens (VDIOR, DDIOR: $U=0.46 ; p=0.64 ; n=22$ ). The distance between the membranous processes of the ventral bar is not a reliable measurement because it differed between mounted and live specimens or the membranous processes could not be seen clearly. In contrast to Rubtsova et al. (2006), no difficulty was found in obtaining an accurate measurement of the whole length of the penis either for live or mounted specimens.

\section{Discussion}

This study reports for the first time the occurrence of a Ligophorus species in the host Mugil platanus and of this genus in the South Atlantic Ocean.

The similarity among species has led to erroneous identifications. In many cases, a single species was split into different species based on detailed morphological and morphometric analyses of the sclerotized structures of the haptor (dorsal and ventral bars, dorsal and ventral anchors) and of the genital organs (terminal genitalia of male copulatory complex, vagina), and on the occurrence of Ligophorus specimens in mullets from different geographic areas. This is illustrated in the following examples: (1) the separation of L. gussevi Miroshnichenko et Maltsev, 2004 (synonymous of L. pilengas Sarabeev et Balbuena, 2004, according to Balbuena et al. 2006) from L. chabaudi Euzet et Suriano, 1977; (2) the separation of 
L. mediterraneus Sarabeev, Balbuena et Euzet, 2005 cited for the Mediterranean Sea, from specimens formerly assigned to L. mugilinus by Euzet and Suriano (1977); and (3) L. vanbenedenii Parona et Perugia, 1890 cited for the Japan Sea, was first transferred to L. chabaudi by Euzet and Suriano (1977), and then described as a new species, L. domnichi Rubtsova, Balbuena et Sarabeev, 2007 (see Sarabeev and Balbuena 2004; Sarabeev et al. 2005; Balbuena et al. 2006; Rubtsova et al. 2006, 2007).

Based on the features mentioned above, L. uruguayense differs from the following Mediterranean species described by (1) Euzet and Suriano (1977): L. szidati, L. chabaudi, L. macrocolpus, L. acuminatus, L. minimus, L. heteronchus, L. angustus, L. imitans, L. confusus; (2) Euzet and Sanfilippo (1983): L. parvicirrus; (3) Sarabeev et al. (2005): L. mediterraneus; and (4) Rubtsova et al. (2006): L. cephali, on the basis of the shapes of the ventral bar and anchors, the accessory piece of the penis and the vaginal aperture, the host species and the geographic distribution. Additionally, Ligophorus uruguayense differs from L. euzeti Dmitrieva et Gerasev, 1996, L. gussevi, L. llewellyni Dmitrieva, Gerasev et Pron'kina, 2007 , and the three recently described species from the Japan Sea by Rubtsova et al. (2007): L. domnichi, L. cheleus and L. pacificus, mainly in the shape of the accessory piece of the penis, the host species and the geographic distribution.

Several species of Ligophorus have been described from Chinese mullets. Ligophorus hamulosus Pan et Zhang, 1999, L. chenzhenensis $\mathrm{Hu}$ et Li, 1992 and L. chongmingensis $\mathrm{Hu}$ et Li, 1992 differ from L. uruguayense in the shape of the dorsal or ventral bars and the penis accessory piece (Hu and Li 1992, Pan 1999). Although the descriptions of three species cited by Zhang et al. (2003) (L. ellochelon Yang, 2001, L. kaohsianghienis (Gussev, 1962) and L. leporinus (Zhang et Ji, 1981) were not available for comparison, they may not be identical to L. uruguayense, as suggested by their different hosts and distant location.

Ligophorus uruguayense is similar to L. mugilinus from the North Atlantic Ocean, as redescribed by Sarabeev et al. (2005), by having the ventral bar larger than the dorsal bar, but can be distinguished from it by the shape of the sclerotized median process, the membranous anterior process, and the absence of a sclerotized thickening at its base. Ligophorus mugilinus has a claw-shaped penis accessory piece and a vaginal tube of uniform diameter, while L. uruguayense has a J-shaped penis accessory piece and a convoluted vaginal tube of variable diameter along its length. In L. uruguayense the guard and shaft of the ventral anchor differ slightly in length, and the guard shows a thick process at the distal end where the ventral connecting bar articulates with the anchor. In contrast, the guard and shaft of L. mugilinus differ considerably in length, and the guard is only slightly thickened at the distal end in some specimens (Sarabeev et al. 2005).

Ligophorus huitrempe is morphometrically similar to L. uruguayense but differs from this species in its ventral bar with two anterior thickenings; in lacking the median sclerotized and the membranous processes; in the absence of a thick process at the distal end of the guard; in its U-shaped penis accessory piece, which shows a thickening at the distal end of the upper lobe; and in that its vagina is uniformly sclerotized and opens mid-laterally. Although both L. mugilinus and L. huitrempe parasitize Mugil cephalus, they were found in geographically distant areas (the former in the North Atlantic and the latter in the South Pacific).

It is concluded that L. uruguayense should be erected as a new species based on its morphological differences (ventral bar, ventral anchors, penis accessory piece and vagina), distinct host species and a dissimilar geographical distribution.

Acknowledgements. Thanks are due to R. Porta Abayian and W Pérez for providing mullets from Las Flores, to O. Volonterio and R. Ponce de León for their help and comments, and to J.A. Balbuena and V.L. Sarabeev for providing valuable bibliography. Two anonymous reviewers provided comments that improved the manuscript.

\section{References}

Balbuena J.A., Rubtsova N.Y., Sarabeev V.L. 2006. Ligophorus pilengas Sarabeev and Balbuena, 2004 (Monogenea: Ancyrocephalidae) is proposed as the senior synonym of $L$. gussevi Miroshnichenko and Maltsev, 2004. Systematic Parasitology, 63, 95-98. DOI: 10.1007/s11230-005-9000-z.

Castro González M., Heras S., Cousseau M.B., Roldán M.I. 2008. Assessing species validity of Mugil platanus Günther, 1880 in relation to Mugil cephalus Linnaeus, 1758 (Actinopterygii) Italian Journal of Zoology, 75, 319-325. DOI: 10.1080/11250. 000801886254

Dmitrieva E.V., Gerasev P.I. 1996. Monogenean of the genus Ligophorus (Ancyrocephalidae), parasites of the Black Sea mullets (Mugilidae). Parazitologiya, 30, 440-449 (In Russian).

Dmitrieva E.V., Gerasev P.I., Pron'kina N.V. 2007. Ligophorus llewellyni n. sp. (Monogenea: Ancyrocephalidae) from the redlip mullet Liza haematocheilus (Temninck and Schlegel) introduced into the Black Sea from the Far East. Systematic Parasitology, 67, 51-64. DOI: 10.1007/s11230-006-9072-4.

Euzet L., Sanfilippo D. 1983. Ligophorus parvicirrus n. sp. (Monogenea, Ancyrocephalidae) parasite de Liza ramada (Risso, 1826) (Teleostei, Mugilidae). Annales de Parasitologie Humaine et Comparée, 58, 325-335.

Euzet L., Suriano D.M. 1977. Ligophorus n. g. (Monogenea, Ancyrocephalidae) parasite des Mugilidae (Téléostéens) en Méditerranée. Bulletin du Muséum Nationale d'Histoire Naturelle, 3e Série, Zoologie, 472, 799-821.

Fernández Bargiela J. 1987. Los parásitos de la Lisa Mugil cephalus L. en Chile: Sistemática y aspectos poblacionales (Perciformes: Mugilidae). Gayana Zoologia, 51, 3-58.

Fraga E., Schneider H., Nirchio M., Santa-Brigida E., RodriguesFilho L.F., Sampaio I. 2007. Molecular phylogenetic analyses of mullets (Mugilidae, Mugiliformes) based on two mitochondrial genes. Journal of Applied Ichthyology, 23, 598-604. DOI: $10.1111 / \mathrm{j} .1439-0426.2007 .00911 . x$.

Hargis W.J. 1955. Monogenetic trematodes of Gulf of Mexico fishes. Part X. The family Microcotylidae Taschenberg, 1879. Transactions of the American Microscopical Society, 75, 436-453.

Hu Z.Y., Li D.X. 1992. Two new species of monogenetic trematodes of marine fishes Mugil cephalus from the Chongmin Island, Shangai, China. Journal of Shanghai Teacher's University (Natural Sciences), 21, 67-70.

Juárez-Arroyo J., Salgado-Maldonado G. 1989. Helmintos de la "lisa" Mugil cephalus Lin. en Topolobampo Sinaloa, México. Ana- 
les del Instituto de Biología, Universidad Nacional Autónoma de México, 60, 279-298.

Langeron M. 1942. Précis de Microscopie. Masson and Cie, Paris, $1340 \mathrm{pp}$.

Mariniello L., Ortis M., D’Amelio S., Petrarca V. 2004. Morphometric variability between and within species of Ligophorus Euzet and Suriano, 1977 (Monogenea: Ancyrocephalidae) in the Mediterranean Sea. Systematic Parasitology, 57, 183-190. DOI: 10.1023/B:SYPA.0000019080.43784.06.

Pan J. 1999. Monogenea of marine fishes from Hainan Island V. One new species of the genus Ligophorus from the South China Sea. Zoology Research, 20, 186-188 (In Chinese).

Paperna I., Overstreet M. 1981. Parasites and diseases of mullets (Mugilidae) In: (Ed. O.H. Oren) Aquaculture of Grey Mullets. International Biological Program 26, Cambridge University Press, 508 pp.

Rubtsova N.Y., Balbuena J.A., Sarabeev V.L. 2007. Three new species of Ligophorus (Monogenea: Dactylogyridae) on the gills of Mugil cephalus (Teleostei: Mugilidae) from the Japan Sea. Journal of Parasitology, 93, 772-780. DOI: 10.1645/GE884R.1.

Rubtsova N.Y., Balbuena J.A., Sarabeev V.L., Blasco-Costa I., Euzet L. 2006. Description and morphometrical variability of a new species of Ligophorus and of Ligophorus chabaudi (Monogenea: Dactylogyridae) on Mugil cephalus (Teleostei) from the Mediterranean Basin. Journal of Parasitology, 92, 486-495. DOI: $10.1645 / \mathrm{GE}-747 \mathrm{R} .1$.

Sarabeev V.L., Balbuena J.A. 2004. Ligophorus pilengas n. sp. (Monogenea: Ancyrocephalidae) from the introduced so-iuy mullet, Mugil soiuy (Teleostei: Mugilidae) in the Sea of Azov and the Black Sea. Journal of Parasitology, 90, 222-228. DOI: 10.1645/GE-163R.

Sarabeev V.L., Balbuena J.A., Euzet L. 2005. Taxonomic status of Ligophorus mugilinus (Hargis, 1955) (Monogenea: Ancyrocephalidae), with a description of a new species of Ligophorus from Mugil cephalus (Teleostei: Mugilidae) in the Mediterranean Basin. Journal of Parasitology, 91, 1444-1451. DOI: 10.1645/GE-418R.1.

Valles-Rios M.E., Ruiz-Campos G., Galaviz-Silva L. 2000. Prevalencia e intensidad parasitaria en Mugil cephalus (Pisces: Mugilidae), del Río Colorado, Baja California, México. Revista de Biología Tropicale, 48, 495-501.

Zhang J., Yang T., Liu L., Ding X. 2003. A list of monogeneans from Chinese marine fishes. Systematic Parasitology, 54, 111-130. DOI: $10.1023 / \mathrm{A}: 1022581523683$. 